\title{
Some Characteristics of Stedman Packing in the Distillation of Hydrogen and Its Isotopes
}

\author{
Abraham Fookson, Philip Pomerantz, and Simon Rothberg
}

\begin{abstract}
Apparatus was designed and constructed in which some characteristics of Stedman packing in the distillation of hydrogen isotopes were measured. The average still hold-up and the hold-up at various boil-up rates were measured using both hydrogen and deuterium as still charge. Mixtures of hydrogen-hydrogen deuteride of known composition were distilled at boil-up rates of 454 milliliters per hour and 1,190 milliliters per hour, respectively. From the distillation data the height equivalent to a theoretical plate was calculated and found to be 1.0 inch for the 12 -inch packing used in these experiments.
\end{abstract}

\section{Introduction}

This investigation was undertaken to determine some of the characteristics of Stedman [7] ${ }^{1}$ packing of value in engineering calculations relating to the distillation of hydrogen isotopes. Specifically, the still hold-up at various boil-up rates and the efficiency of the packing in fractionating hydrogen-hydrogendeuteride mixtures were studied, and the flood point determined. To obtain these data, measurements were made with a Stedman still that was designed for use at very low temperatures.

\section{Apparatus and Material}

The apparatus, similar to that described previously [1], is shown assembled in figure 1 . It consisted of a still, A, with a 25 - by $300-\mathrm{mm}$ stainless-steel Stedmanpacked section and a graduated pot of 50-ml capacity, shown in detail in figure 2 . A cylinder, integral with the still, surrounded the condenser and served as a reservoir for the liquid hydrogen coolant. The vacuum jacket of this cylinderical portion was continuous with that of the still itself. The still was surrounded by a dewar (not shown) filled with liquid nitrogen and was connected to a manometer, B, enabling the pressure in the still to be read. When stopcock C was closed the still could be operated under total reflux conditions, when $\mathrm{C}$ was open, admission of charge or withdrawal of distillate was possible. A regular valve, D, operated by solenoid $\mathrm{E}$, permitted control of the rate of distillation. This regulator consisted of a length of small diameter drill rod fixed to an iron core. The drill rod fit loosely into a glass capillary, the length of the rod in the capillary being controllable by the solenoid, the annular space through which the gas had to pass was thereby variable.

The regulator valve led to a graduated Toepler pump, F, of 500-ml capacity, and to a bypass, G. The latter was used when charging or evacuating the still. The top of the Toepler pump was connected to a manometer. The readings on manometers $\mathrm{B}$ and $\mathrm{H}$ indicated the pressure differential across the regulator, D. A length of pressure rubber tubing, J, led from the Toepler pump to a mercury

1 Figures in brackets indicate the literature references at the end of this paper. reservoir. Raising or lowering of this reservoir permitted adjustment of the mercury level in the Toepler pump and consequently of the pressure within it. This, together with the regulator valve setting, constituted the method of distillation rate control used in this work.

The Toepler pump led to a manifold to which were affixed the bulbs for receiving samples (about $20 \mathrm{ml}$ each), and the calibrated 5,000-ml flasks ${ }^{2}$ used for storing hydrogen deuteride and collecting distillate. The manifold was in turn connected to a mercury diffusion pump. A line (not shown in fig. 1) between the Toepler pump and the diffusion pump bypassed the manifold, enabling the evacuation of the system whether or not bulbs were affixed to the manifold.

The hydrogen gas $\left(99.97 \% \quad \mathrm{H}_{2}\right)$ used in this work was identical with that used in the preparation of liquid hydrogen at the Bureau. It was prepared at the low temperature laboratory of the Bureau by

${ }_{2}^{2}$ These receivers were calibrated with the assistance and equipment of the Volumetric Glassware Section of the Bureau.

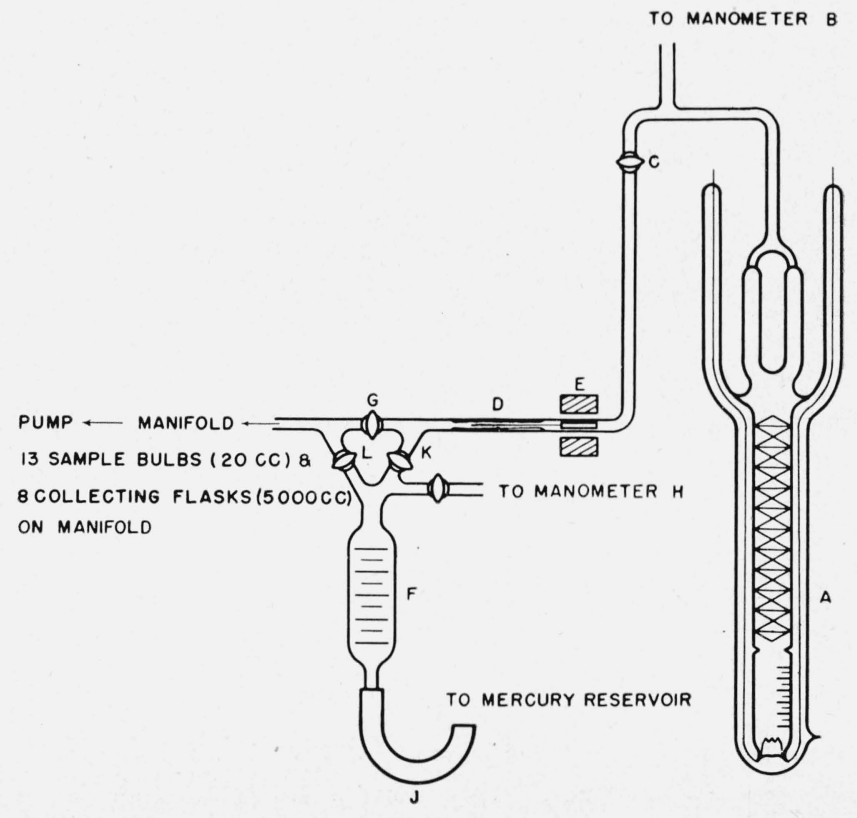

Figure 1. Assembly of distillation apparatus. 


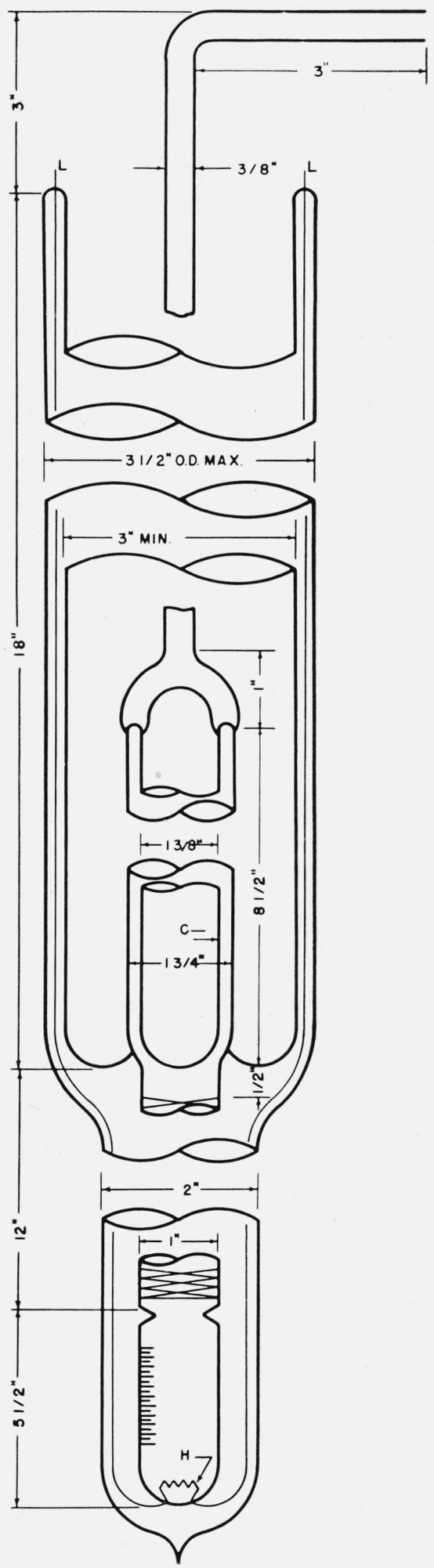

Figure 2. Detail of still.

C, Condenser; H, heater, No. 34 Constantan. Heater leads to go through No. 18 Kovar wire through glass rectifying section to be 1-in. by 1 -in. Stedman F packing. L,'Heater leads, $\$$ No. 20 copper wire. the electrolysis of potassium hydroxide solution and pumped into a steel cylinder of convenient size.

The hydrogen deuteride was prepared by the method of Wender, Friedel, and Orchin [2], involving the reaction at $0^{\circ} \mathrm{C}$ between lithium aluminum hydride and deuterium oxide. For this work, about 50 liters of hydrogen deuteride was prepared, consisting of about 98.5 percent of $\mathrm{HD}, 1$ percent of $\mathrm{H}_{2}$, and 0.5 percent of $\mathrm{D}_{2}{ }^{3}$ This material was used without purification, allowance being made for the hydrogen content when mixtures to be distilled were prepared.

\section{Technique}

\subsection{Hold-up Measurements}

The apparatus was cooled by filling the appropriate Dewars with liquid hydrogen and nitrogen. A quantity of hydrogen or deuterium, about $50 \mathrm{ml}$ liquid as measured in the still-pot, was then introduced into the still as gas, and permitted to liquefy, stopcock C (fig. 1) was closed, and the exact volume noted. Current was then passed through the heater, and the volume in the still-pot and the pressure in the still were noted when equilibrium had been established. The difference between the initial volume and the equilibrium volume was taken as the hold-up corresponding to the boil-up rate as calculated from the heat input. This was repeated for various values of the current.

The results of these experiments had to be corrected for three factors. 1. There existed a heat leak into the still from the exterior, whose magnitude was estimated. 2. The initial volume as measured by means of the graduations on the still-pot was less than the amount of material actually in the still, since an unknown amount was present wetting the column (static hold-up). 3. At each boil-up rate, the volume as read on the still-pot graduations at equilibrium did not take into account the volume of the bubbles in the liquid.

\subsection{Heat Leak and Static Hold-up}

The magnitude of the heat leak was computed from the results of two subsequent experiments. The first experiment was performed by charging hydrogen into the still and reducing the pressure by means of the vacuum pump so that the liquid would boil at a temperature below that of the condenser. The vacuum pump was isolated from the system by closing stopcocks $\mathrm{G}$ and $\mathrm{L}$, and hydrogen gas was withdrawn with the Toepler pump at such a rate that the still pressure remained constant. The time rate of withdrawal of gas was observed, and from the known heat of vaporization of hydrogen, the heat leak was calculated. This method will be referred to as the "withdrawal method" in later discussion.

The second method employed for estimating the heat leak consisted of introducing into the still a

${ }_{3}$ All analyses of gas mixtures reported in this work were made by the Mass Spectrometry Laboratory of the NBS. 
quantity of hydrogen, reducing the pressure to a measured low value, and observing the time necessary for the pressure to rise to its normal equilibrium value. From the known heat capacity of the still contents (the still itself having negligible heat capacity at $20^{\circ} \mathrm{K}$ ), the heat necessary to produce this pressure rise was calculated. This method will be referred to as to the "time method".

The second factor, that of the "zero" point volume, or "static" hold-up, was computed by introducing a measured quantity of hydrogen deuteride into the empty still and observing the volume of liquid that appeared in the pot. The difference in volume represented the material that wet the packing plus the amount of reflux occasioned by the heat leak into the pot.

The third factor, the augmentation in liquid volume in the pot because of the gas bubbles, could not be corrected, and volumes had to be estimated at the higher boil-up rates.

\subsection{Distillation}

The distillations conducted in this work were carried out with the apparatus shown in figure 1. After the appropriate vessels were cooled with liquid nitrogen and liquid hydrogen, a charge of hydrogen deuteride was admitted to the still from the storage flasks on the manifold. The Toepler pump was used to withdraw the hydrogen deuteride from the flasks after the equilibrium pressure of about $450 \mathrm{~mm}$ had been reached. From the initial and final pressures in the flasks, and their volumes, the quantity of hydrogen deuteride in the still was calculated. The volume in the still-pot was then noted, and hydrogen gas was introduced from a tank until the volume was increased to a predetermined amount. The assumption was made here that the hold-up in the column (calculated volume of hydrogen deuteride introduced minus volume neasured in still-pot) would remain approximately unchanged, and hence the increase in volume represented hydrogen introduced.

Current was then passed through the still heater to provide a predetermined boil-up rate, while stopcock C was closed. The pressure as read on manometer B was noted from time to time, and when this was constant, distillation was started. Stopcock $\mathrm{C}$ was opened, regulator $\mathrm{D}$ was adjusted, and the Toepler pump allowed to fill up, by continuously lowering the mercury reservoir, at such a rate as to correspond to a predetermined reflux ratio. Each time the Toepler pump was full $(500 \mathrm{ml})$, stopcock $\mathrm{K}$ was closed and $\mathrm{L}$ opened, thereby discharging the contents to either the vacuum pump, a sample bulb, or a collecting flask. Samples were collected at intervals suitably spaced during the distillation, so as to give a representative curve when the composition of distillate was plotted against amount distilled as measured by volumes in the Toepler pump and pressures read on manometer $\mathrm{H}$ (fig. 1). All gas volumes were corrected to $0^{\circ} \mathrm{C}$ and $760-\mathrm{mm}$ pressure. Analyses on the several samples were determined with the mass spectrograph.
The still pressure was noted during the course of the distillation, and when it had fallen to a constant value it was presumed that the material in the still was then pure hydrogen deuteride. This pressure corresponded to the condensation temperature of hydrogen deuteride at the boil-up rate used in the experiment. Since it was a function of the rate of heat input to the still, it was not the same from run to run.

\section{Results}

\subsection{Hold-up Measurements}

The data obtained in the first experiment relating boil-up rate with hold-up, using hydrogen as still charge, are given in table 1 . The temperature, $T$, in the still was calculated from the observed pressure, $P$, by means of the following equation [3]

$$
\log _{10} P\left(n-\mathrm{H}_{2}\right)=4.66687-\frac{49.956}{T}+0.020537 T \text {. }
$$

From this temperature, the molar heat of vaporization, $L_{v}$, was computed, using the following equation [3]

$$
L_{v}\left(n-\mathrm{H}_{2}\right)=219.7-0.27(T-16.6)^{2} .
$$

The molar volume of the liquid, $V_{m}$ ( $\left.\mathrm{ml} / \mathrm{mole}\right)$, at the appropriate temperature was obtained by use of the following equation [8]

$$
V\left(n-\mathrm{H}_{2}\right)=24.747-0.08005 T+0.012716 T^{2} .
$$

From the values of $L_{v}$ (cal/mole), $V_{m}$ (ml/mole), the heater current, $I,(\operatorname{amp})$, and the heater resistance of $46 \mathrm{ohms}$, the boil-up rate of the liquid, $B,(\mathrm{ml} / \mathrm{hr})$ was calculated using the equation (derived from the definitions of the quantities concerned).

$$
B=\frac{I^{2} V_{m}}{L_{v}} \times 3.96 \times 10^{4} .
$$

The constant factor $3.9 \times 10^{4}$ includes the heater

\begin{tabular}{|c|c|c|c|c|c|c|c|c|}
\hline$I$ & $\begin{array}{c}\text { Barom- } \\
\text { eter } \\
\text { pres- } \\
\text { sure }\end{array}$ & $\begin{array}{l}\text { Abso- } \\
\text { lute } \\
\text { pres- } \\
\text { sure in } \\
\text { still }\end{array}$ & $\begin{array}{c}\text { Equi- } \\
\text { librium } \\
\text { tem- } \\
\text { pera- } \\
\text { ture }\end{array}$ & $L_{v}$ & $V_{n}$ & $\begin{array}{l}\text { Boil-up } \\
\text { rate }\end{array}$ & $\begin{array}{l}\text { Vol- } \\
\text { ume in } \\
\text { still }\end{array}$ & $\begin{array}{l}\text { Hold- } \\
\text { up a }_{(\Delta V)}\end{array}$ \\
\hline$m a$ & $m m$ & $m m$ & ${ }^{\circ} K$ & cal/mole & $\mathrm{ml} / \mathrm{mole}$ & $m l / h r$ & $m l$ & $m l$ \\
\hline 0 & 753.4 & 771.4 & 20.45 & 215.7 & 28.43 & & 46.0 & 5.7 \\
\hline 80 & 753.4 & 791.9 & 20.52 & 215.5 & 28.47 & 33.5 & 44.0 & 7.7 \\
\hline 150 & 753.4 & 810.4 & 20.62 & 215.3 & 28.52 & 118 & 41.5 & 10.2 \\
\hline 200 & 752.9 & 873.9 & 20.89 & 214.7 & 28.66 & 211 & 40.0 & 11. 7 \\
\hline 250 & 752.9 & 931.9 & 21.11 & 214. 2 & 28.77 & 333 & 38.5 & 13. 2 \\
\hline 310 & 752.9 & 1015.9 & 21.42 & 213.4 & 28.93 & 516 & 37.5 & 14. 2 \\
\hline 370 & 752.6 & 1106.6 & 21.74 & 212.6 & 29.18 & 744 & 36.5 & 15. 2 \\
\hline 420 & 752.6 & 1183.6 & 21.98 & 211.9 & 29.22 & 965 & 35.5 & 16. 2 \\
\hline 490 & 752.6 & 1358.6 & 22.52 & 210.2 & 29.80 & 1347 & 34.5 & 17. 2 \\
\hline 540 & 752.4 & 1496.4 & 22.93 & 208.9 & 30.35 & 1679 & 33.0 & 18.7 \\
\hline
\end{tabular}
resistance value and the necessary conversion factors.

Flooding was first observed, using $n$-deuterium as

TABLE 1. Hold-up measurements with hydrogen

a Corrected by adding $5.7 \mathrm{ml}$ (average of experiments 1 to 3 , table 3 ) to observed results. 
TABLE 2. Hold-up measurements wit' deuterium

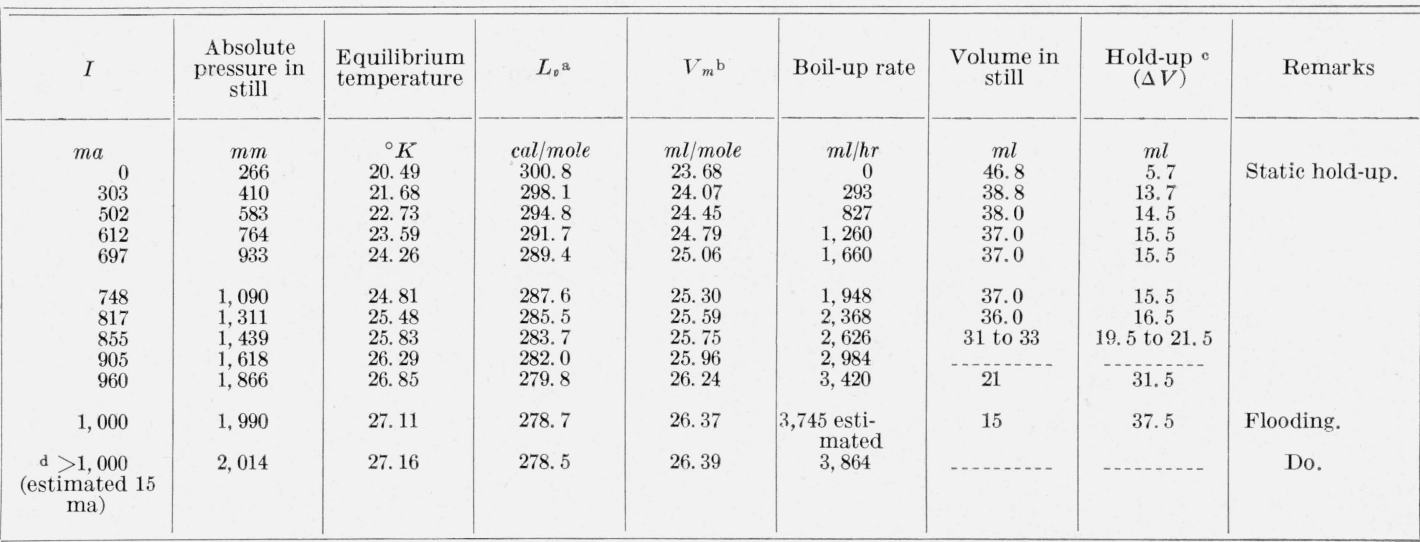

a Calculated by adding $85.2 \mathrm{cal} /$ mole (difference between $n-\mathrm{D}_{2}$ and $n-\mathrm{H}_{2}$ at $19.70^{\circ} \mathrm{K}$ ) to corresponding value of $n-\mathrm{H}_{2}$.

b $V_{m}(\mathrm{ml} / \mathrm{mole})=22.965-0.2460 T+0.0137 T^{2}$.

still charge, at a boil-up rate of $3,745 \mathrm{ml} / \mathrm{hr}$, at which rate the pressure in the still was $1,990 \mathrm{~mm} \mathrm{Hg}$. 'This corresponded to a vapor velocity of $0.26 \mathrm{ft} / \mathrm{sec}$. In a previous experiment using hydrogen as still charge, the column could not be induced to flood within the limits of the apparatus. The controlling factor here was the manometer, B (fig. 1), whose upper limit was about $2,000 \mathrm{~mm} \mathrm{Hg}$.

In the case of deuterium, as the boil-up rate increased from the lower values, the level of liquid at the edges of the plates was substantially constant, increasing from approximately $1 \mathrm{~mm}$ at $2,626 \mathrm{ml} / \mathrm{hr}$ to about $3 \mathrm{~mm}$ at $3,420 \mathrm{ml} / \mathrm{hr}$. But as the flood point was neared the amount of liquid continued to increase in the top third of the column. Shortly, on the top plate, liquid completely covered the cone and continued to increase until a column of liquid started to enter the condenser. This boil-up rate was designated as the flood point.

The calculation of the boil-up rates when deuterium was used in the hold-up measurements are not as accurate as were those when hydrogen was used. This is a consequence of the fact that there does not exist a reported heat of vaporization-temperature relationship for deuterium as there does for hydrogen. Hence, the deuterium analogues of eq 2 and 3 could not be employed. An approximation was obtained for the heats of vaporization of deuterium at various temperatures $\left(L_{v}\right.$, table 2$)$ by drawing a curve through the single reported value, $302.3 \mathrm{cal} /$ mole at $19.70^{\circ} \mathrm{K}$, parallel to the corresponding curve for hydrogen as derived from eq 2 . The error in this approximation was not estimated.

The hold-up at, and in the neighborhood of, the flood point, was exceedingly difficult to measure by the technique employed here. This was due to the inability of accurately determining the volume of liquid in the pot because of the violence of the boiling. An attempt was made to eliminate this difficulty by momentarily switching off the heater current and immediately reading the volume. However, this method proved unfeasible, because before the gas bubbles ceased rising the liquid volume was e Corrected by adding $5.7 \mathrm{ml}$ (average of experiments 1 to 3 , table 3 ) to observed results.

d Off scale.
TABLE 3. Static hold-up measurements

\begin{tabular}{|c|c|c|c|c|c|}
\hline \multirow{2}{*}{$\begin{array}{l}\text { Experi- } \\
\text { ment }\end{array}$} & \multicolumn{3}{|c|}{ Material introduced into still } & \multirow{2}{*}{$\begin{array}{l}\text { Volume } \\
\text { observed } \\
\text { in pot }\end{array}$} & \multirow{2}{*}{$\begin{array}{c}\text { Static } \\
\text { hold-up }\end{array}$} \\
\hline & $\mathrm{HD}$ & $\mathrm{H}_{2}$ & Total & & \\
\hline $\begin{array}{l}1 \ldots \ldots \\
2 \ldots \ldots \\
3 \ldots \\
4 \ldots\end{array}$ & $\begin{array}{l}m l \\
16.2 \\
26.5 \\
16.6 \\
31.9\end{array}$ & $\begin{array}{r}m l \\
0.3 \\
.5 \\
.3 \\
1.2\end{array}$ & $\begin{array}{l}m l \\
16.5 \\
27.0 \\
16.9 \\
33.1\end{array}$ & $\begin{array}{l}m l \\
11.0 \\
21.2 \\
11.0 \\
26.2\end{array}$ & $\begin{array}{l}m l \\
5.5 \\
5.8 \\
5.9 \\
6.9\end{array}$ \\
\hline
\end{tabular}

changing rapidly due to the return of reflux from the column. The difficulty in accurately reading the volume under the circumstance described was undoubtedly the major factor in accounting for the discrepancy in the values for the hold-up when hydrogen (table 1) and the deuterium (table 2) were used. However, in both cases, the order of magnitude is believed to be correct.

The results of the "static" hold-up determinations are shown in table 3 . In these experiments hydrogen deuteride was used. The results were used to correct the observed values of the hold-up in both the hydrogen and the deuterium experiments. The figures for the hold-up in tables 1 and 2 are the corrected values.

In computing the correction due to the static hold-up, experiment 4 of table 3 was rejected as being evidently in error. The much higher percentage of hydrogen present in the charge $(5 \%$, as opposed to $1.5 \%$ in the other three cases) would tend to give high results, since, through fractionation, this material would be localized in the column. The average of the first three experiments was therefore taken as the correction to be applied in tables 1 and 2 .

\subsection{Heat-Leak Measurements}

a. Calculation from Still Dimensions

At an atmospheric pressure of $753 \mathrm{~mm}$, the pressure inside the still was $771 \mathrm{~mm}$, with no current 
flowing in the heater coil. This pressure differential corresponded to a temperature differential of $0.073^{\circ}$, from eq 1 . Since the condenser wall thickness, $L$, was $0.075 \mathrm{~cm}$, and its area, $A$, was $493 \mathrm{~cm}^{2}$, the rate at which heat was entering and leaving the system to maintain a steady state was obtained from the equation

$$
\frac{d Q}{d t}=-K A \frac{d T}{d L}
$$

Using a value ${ }^{4}$ for $K$ of $3 \times 10^{-4} \mathrm{cal} \mathrm{cm}^{-1} \mathrm{sec}^{-1} \mathrm{deg}^{-1}$, this rate was $0.144 \mathrm{cal} / \mathrm{sec}$, or from eq 4 , equivalent to a boil-up rate of $70 \mathrm{ml} / \mathrm{hr}$.

This value is undoubtedly too high, since the figure used for the effective area of the condensing surface is excessive. This was indicated by the fact that the pressure in the still was not dependent upon the level of liquid hydrogen coolant in the condenser over a wide range of levels, when there was no heat input. In addition, the condensing gas-condenser wall and condenser wall-coolant liquid temperature differentials were not taken into account. These differentials may exceed that across the condenser wall itself, though the latter is the one employed in the $d T / d L$ term in the eq 5 .

\section{b. Time Method}

The "time method", described above, yielded values of 2.5 and $2.0 \mathrm{ml} / \mathrm{hr}$, for the boil-up rate equivalent to the heat leak as the results of two experiments (table 5). Though these values possess the merit of consistency, objections can be raised to the experimental method used. The assumption implicit in the method is that when the pressure was reduced, the entire body of liquid in the still was in thermal equilibrium. This was probably not realized in practice, since cooling through evaporation would occur at the surface of the liquid, and the remainder would have to be cooled by convection. Moreover, thermal equilibrium would most likely be absent throughout the entire experiment, as the pressure rose, since the convection would be slow. In addition, the amount of material in the column, and its thermal state, was not known. Because of these considerations, the validity of the time method for measuring the heat leak is open to question.

\section{c. Withdrawal Method}

In the opinion of the authors, the best method for measuring the heat leak is the "withdrawal method",

${ }_{4}^{4}$ This value was obtained by applying eq 5 to the known operating conditions and dimensions of the still used in previous work [1]. in which the rate at which liquid is vaporized at constant pressure as a consequence of the heat leak was measured. The results are given in table 4. In this case, the question of thermal equilibrium did not arise, since the entire process occurred at constant temperature. Also, the quantity of material in the still was of no consequence, since the heat leak was probably independent of the height of liquid in the still pot.

TABLE 4. Heat-leak measurements by withdrawal method

\begin{tabular}{|c|c|c|c|c|c|}
\hline Experiment & $\begin{array}{l}\text { A bsolute P } \\
\text { in still }\end{array}$ & $\begin{array}{l}\text { Gas col- } \\
\text { lected at } \\
\text { STP }\end{array}$ & Time & Heat leak & $\begin{array}{c}\text { Corre- } \\
\text { sponding } \\
\text { boil-up rate }\end{array}$ \\
\hline $\begin{array}{l}1 \ldots \ldots \\
2 \ldots \\
3 \\
4\end{array}$ & $\begin{array}{r}m m \\
443 \\
507 \\
371 \\
443\end{array}$ & $\begin{array}{l}m \ell \\
244 \\
213 \\
202 \\
217\end{array}$ & $\begin{array}{l}\min \\
1.54 \\
1.13 \\
2.00 \\
1.91\end{array}$ & $\begin{array}{c}\mathrm{cal} / \mathrm{hr} \\
93.6 \\
95.5 \\
59.6 \\
65.4\end{array}$ & $\begin{array}{c}m l / h r \\
12.1 \\
12.3 \\
7.7 \\
8.4\end{array}$ \\
\hline
\end{tabular}

The inconsistencies found in the values in table 4 can probably be explained by taking into account two experimental factors. First, the Toepler pump was an inaccurate flowmeter. It was operated manually, the mercury level being lowered at such a rate that the still pressure remained constant; this was quite difficult to accomplish at a uniform rate. Second, the condition of thermal equilibrium was undoubtedly disturbed each time the pressure was reduced or permitted to increase, for the reasons pointed out in the discussion of the time method. However, the values were sufficiently close together to safely assert that the heat leak was equivalent to a boil-up rate of about $10 \mathrm{ml} / \mathrm{hr}$. This was shown to be at least qualitatively true by the fact that the vigor of the boiling in the first hold-up measurement at $33.5 \mathrm{ml} / \mathrm{hr}$ (table 1 ) was very much greater than that at zero current input. At any rate, it is certain that whichever of the above heat leak measurements is nearest the truth, it is a factor of little consequence at the higher boil-up rates.

\subsection{Distillation Measurements}

Two distillations were carried out at boil-up rates of $465 \mathrm{ml} / \mathrm{hr}$ and $1,190 \mathrm{ml} / \mathrm{hr}$. The results of these are listed in tables 6 and 7 , and are shown in figures in figures 3 and 4 , respectively. Because of difficulty in manual control of the level in the Toepler pump and the continuous adjustment of the take-off regulator, constant reflux ratios were difficult to maintain though the order of magnitude was the same in both cases.

As can be seen from figures 3 and 4 , the efficiency of

TABLE 5. Heat-leak measurements by time method

\begin{tabular}{|c|c|c|c|c|c|c|c|c|c|c|}
\hline \multirow{2}{*}{$\begin{array}{c}\text { Experi- } \\
\text { ment }\end{array}$} & \multicolumn{2}{|c|}{ Absolute $P$ in still } & \multicolumn{2}{|c|}{ Temperature } & \multirow{2}{*}{ Time } & \multicolumn{2}{|c|}{ Volume in still } & \multirow{2}{*}{$\Delta V$} & \multirow{2}{*}{\multicolumn{2}{|c|}{ Heat leak }} \\
\hline & Initial & Final & Initial & Final & & Initial & Final & & & \\
\hline $\begin{array}{l}1 \\
2\end{array}$ & $\begin{array}{r}m m \\
283 \\
276\end{array}$ & $\begin{array}{l}m m \\
772 \\
768\end{array}$ & $\begin{array}{l}{ }^{\circ} K \\
17.71 \\
17.40\end{array}$ & $\begin{array}{l}{ }^{\circ} \mathrm{K} \\
20.45 \\
20.43\end{array}$ & $\begin{array}{r}\text { sec } \\
\quad 27 \\
33\end{array}$ & $\begin{array}{l}m l \\
25.0 \\
21.5\end{array}$ & $\begin{array}{l}m l \\
25.3 \\
20.0\end{array}$ & $\begin{array}{l}-0.3 \\
+1.5\end{array}$ & $\begin{array}{c}c a l / h r \\
19.0 \\
15.2\end{array}$ & $\begin{array}{r}m l / h r \\
2.5 \\
2.0\end{array}$ \\
\hline
\end{tabular}




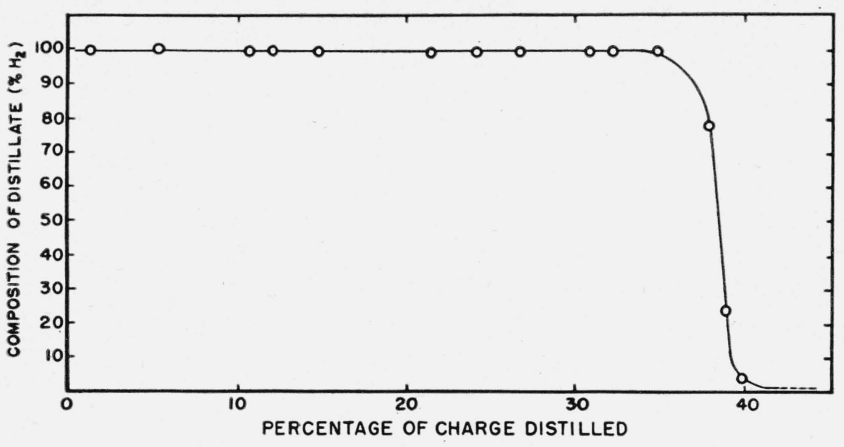

Figure 3. Distillation curve at lower boit-up rate.

TARLE 6. Distillation of $\mathrm{H}_{2}-\mathrm{HD}$ mixture

Charge: 1.03 moles $\mathrm{HD}=68.2$ mole $\%$ 0.48 moles $\mathrm{H}_{2}=31.8$ mole $\%$

Heater resistance: $46 \mathrm{ohms}$

Current input: $318 \mathrm{ma}$

\begin{tabular}{|c|c|c|c|c|c|c|}
\hline \multirow{2}{*}{$\begin{array}{c}\text { Still } \\
\text { pressure }\end{array}$} & \multirow{2}{*}{\multicolumn{2}{|c|}{$\begin{array}{l}\text { Amount distilled } \\
\text { (STP) }\end{array}$}} & \multicolumn{2}{|c|}{ Composition } & \multirow{2}{*}{$\begin{array}{l}\text { Reflux } \\
\text { ratio }\end{array}$} & \multirow{2}{*}{ Fraction } \\
\hline & & & $\mathrm{H}_{2}$ & $\mathrm{HD}$ & & \\
\hline $\begin{array}{l}m m a b s \\
1.025\end{array}$ & $m l$ & $\%$ & & & & \\
\hline $\begin{array}{l}1,025 \\
1,020\end{array}$ & $\begin{array}{r}453 \\
1.812\end{array}$ & $\begin{array}{l}1.34 \\
5.36\end{array}$ & $\begin{array}{l}99.7 \\
99.8\end{array}$ & 0.3 & $\begin{array}{l}110 \\
21\end{array}$ & $\frac{1}{2}$ \\
\hline 1,016 & $\begin{array}{l}3,624 \\
3,624\end{array}$ & $\begin{array}{r}0.70 \\
10.71\end{array}$ & 99.7 & .3 & 55 & 3 \\
\hline 1,005 & 4,077 & 12. 05 & 99.7 & .3 & 62 & 4 \\
\hline 998 & 4,983 & 14.73 & 99.6 & .4 & 55 & 5 \\
\hline 984 & 6,344 & 18.76 & 99.4 & .6 & 62 & 6 \\
\hline 967 & 7,250 & 21.43 & 99.2 & .8 & 69 & 7 \\
\hline 950 & 8,156 & 24. 11 & 99.3 & .7 & 62 & 8. \\
\hline 920 & 9,062 & 26.79 & 99.3 & .7 & 83 & 9 \\
\hline 842 & 10,421 & 30.81 & 99.4 & .6 & 83 & 10 \\
\hline 807 & 10,874 & 32.15 & 99.4 & .6 & 69 & 11 \\
\hline 743 & $\begin{array}{l}10,770 \\
11,7\end{array}$ & 34.80 & $\begin{array}{l}9.4 \\
99.5\end{array}$ & .5 & 93 & 12 \\
\hline 606 & 12,819 & 37.90 & 77.2 & 22.8 & 68 & 13 \\
\hline 600 & 13,166 & 38.93 & 23.7 & 71.3 & 93 & 14 \\
\hline 600 & 13,513 & 39.95 & 3.5 & 96.5 & 100 & 15 \\
\hline 602 & 13,856 & 40.97 & .8 & 99.2 & 85 & 16 \\
\hline
\end{tabular}

TABLE 7. Distillation of $\mathrm{H}_{2}-\mathrm{HD}$ mixture

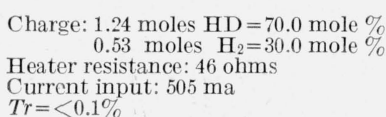

\begin{tabular}{|c|c|c|c|c|c|c|c|}
\hline \multirow{3}{*}{$\begin{array}{c}\text { Still } \\
\text { pressure } \\
m m \text { aps }\end{array}$} & \multirow{2}{*}{\multicolumn{2}{|c|}{$\begin{array}{l}\text { Amount distilled } \\
(\mathrm{STP})\end{array}$}} & \multicolumn{3}{|c|}{ Composition of distillate } & \multirow{2}{*}{$\begin{array}{l}\text { Reflux } \\
\text { ratio }\end{array}$} & \multirow{2}{*}{ Fraction } \\
\hline & & & $\mathrm{H}_{2}$ & $\mathrm{HD}$ & $\mathrm{D}_{2}$ & & \\
\hline & $m l$ & $\%$ & 990 & 10 & & 81 & \\
\hline$\underset{(a)}{1,322}$ & $\begin{array}{c}1,344 \\
(a)\end{array}$ & $\begin{array}{l}1.1 \\
3.4 \\
(a)\end{array}$ & 97.8 & $\begin{array}{l}1.0 \\
2.2\end{array}$ & $\ldots$ & $\begin{array}{l}81 \\
77\end{array}$ & $\begin{array}{l}1 \\
2 \\
3\end{array}$ \\
\hline 1,290 & 5,376 & 13.5 & 93.1 & 6. 9 & -. & 85 & 4 \\
\hline 1,230 & 7,168 & 18.1 & 92.0 & 8.0 & & 63 & 5 \\
\hline 1,150 & 8,980 & 22.6 & 88.0 & 12.0 & $\ldots$ & 76 & 6 \\
\hline 1,112 & 9,876 & 24.9 & $(b)$ & (b) & (b) & 65 & 7 \\
\hline 1,060 & 10,772 & 27.1 & 87.2 & 12.8 & -... & 69 & 8 \\
\hline 998 & 11,668 & 29.4 & 81.6 & 18.4 & & 85 & 9 \\
\hline 950 & 12,564 & 31.7 & 72.0 & 23.0 & $\mathrm{Tr}$ & 57 & 10 \\
\hline 860 & 14,417 & 36.3 & 30.7 & 69.2 & $\operatorname{Tr}$ & (c) & 11 \\
\hline 856 & 14,865 & 37.4 & 21.7 & 78.3 & $\mathrm{Tr}$ & 79 & 12 \\
\hline 838 & 15,322 & 38.6 & 12.7 & 87.2 & 0.1 & 64 & 13 \\
\hline 830 & 15,770 & 39.8 & 9.1 & 90.8 & .1 & 111 & 14 \\
\hline 841 & 16,218 & 41.1 & 9.6 & 90.3 & .1 & 870 & ${ }^{d} 15$ \\
\hline & 17,114 & 43.1 & 4. 9 & 95.0 & .1 & 65 & 16 \\
\hline 843 & 18,110 & 45. 7 & 4.4 & 95.5 & .1 & 119 & 17 \\
\hline 845 & 18,558 & 46.8 & 3.2 & 96.8 & .1 & 55 & 18 \\
\hline
\end{tabular}

a Contaminated sample not analyzed.

b Not taken.

Failed to note time on sample, therefore no reflux ratio obtained.

$d$ Taken after 21 minutes total reflux.

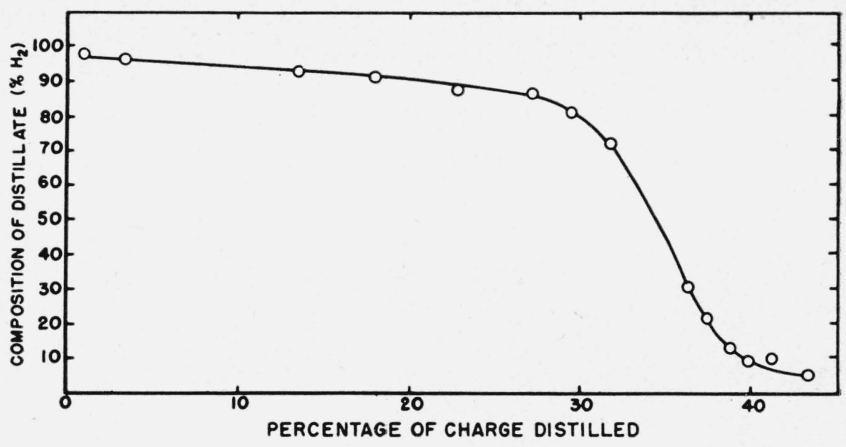

FiguRE 4. Distillation curve at higher boil-up rate.

separation is greater at the lower boil-up rate. At the lower boil-up rate, the shape of the curve shows that the efficiency of the column was above the minimum number of plates necessary for separation. Since the reflux ratio was not absolutely constant, the fact that the points fall on a smooth curve shows that the still efficiency is not dependent upon reflux ratio at this boil-up rate.

At the higher boil-up rate, the efficiency of separation is lower. In figure 4 it is seen that the points do not fall on a smooth curve, probably because of the dependence of separation upon reflux ratio. Thus, at a value of 41.1 percent distilled the reflux ratio rose to 870 to 1 because of a time interval spent in charging sample bulbs; the fractionation of this sample was thus improved noticeably by the refluxing.

\subsection{Estimation of Column Efficiency}

In usual distillation practice, the efficiency of a column is obtained by analyzing simultaneously withdrawn samples from the pot and the head, and computing by analytical or graphical methods the number of theoretical plates required to effect the observed difference in composition $\lceil 4\rceil$. This technique was not applied here because of the experimental difficulties involved in withdrawing a representative sample from the pot. Instead, the distillation data were used to calculate the efficiency of the Stedman column employed in this work. The calculation presented here is that of George Webb [6], of Hydrocarbons Research. Inc. In brief, the method involves computing the composition of the pot liquid at any chosen point in the distillation by making use of the known composition of the material already distilled, together with inferences concerning the composition of the column hold-up. The latter is assumed to vary logarithmically from the pot composition to the head composition. From the knowledge of the analysis of the material in the pot and that of the head at the chosen point in the distillation, the efficiency of the still can be calculated by conventional methods.

Thus, consider the case, in the second distillation (table 7 and figure 4), at the point where $8,000 \mathrm{ml}$ (STP) have already been distilled. The charge initially was 1.77 moles $(39,700 \mathrm{ml} \mathrm{STP})$, and the hold-up was $16 \mathrm{ml}$ liquid, or $12,700 \mathrm{ml} \mathrm{STP}$. Then 
Bottoms $=39,700-8,000-12,700=19,000 \mathrm{ml} \mathrm{STP}$

Top composition (from an enlargement of the appropriate portion of fig. 4$)=89.3$ percent of $\mathrm{H}_{2}=y$.

Distillate composition (average of composition from zero to $8,000 \mathrm{ml}$ distilled $)=94.7$ percent of $\mathrm{H}_{2}$. If $x$ is the mole fraction of hydrogen in the pot liquid,

$$
\begin{aligned}
& 19,000 x+12,700 \frac{(0.893-x)}{\ln \frac{0.893}{x}}+(0.947)(8,000) \\
& =(0.30)(39,700),
\end{aligned}
$$

from which

$$
x=0.042 \text {. }
$$

The average value of the relative volatility, $\alpha$, for $\mathrm{H}-\mathrm{HD}$ mixtures of the composition dealt with here is 1.45 [6]. For a partial condenser, under total reflux conditions, the number of theoretical plates, $n$, is given by $[5]$.

or

$$
\left.\begin{array}{rl}
n+2 & =\frac{\log \left(\frac{y}{1-y}\right)_{\text {top }}\left(\frac{1-x}{x}\right)_{\text {bottom }}}{\log d_{a v}} \\
& =\frac{\log \left(\frac{0.893}{0.107}\right)\left(\frac{0.958}{0.042}\right)}{\log 1.46} \\
& =13.8 \\
n & =11.8 \text { for the packing used } \\
\text { in this work. } & 12 \\
\text { HETP } & =\frac{11.8}{}=1.0 \mathrm{in} .
\end{array}\right\}
$$

Since the reflux in this experiment was not total, the efficiency of the column is undoubtedly higher than that indicated in the above calculation. Calculations made for amounts of distillate other than the $8,000 \mathrm{ml}$ employed in the above example also gave about 1 in. for the HETP. In view of the simplifying assumptions made in these calculations, it is felt that no valid conclusions can be drawn concerning the relation between the HETP and the other variables of the experiment.

\section{References}

[1] A. Fookson, P. Pomerantz, and E. H. Rich, J. Research NBS 4\%, 31 (1951) RP2224.

[2] E. Wender, R. A. Friedel, and J. J. Orchin, J. Am. Chem. Soc. 71, 1140 (1949).

[3] H. W. Woolley, R. B. Scott, and F. G. Brickwedde, J. Research NBS 41, 379 (1948) RP1932.

4] Clark Robinson and Edwin R. Gilliland, Elements of fractional distillation, 4 th ed., p. $118 \mathrm{ff}$ and $174 \mathrm{ff}$ (McGraw-Hill Book Co., Inc., New York, N. Y., 1950).

[5] Clark Robinson and Edwin R. Gilliland, 4th ed., p. 175 (McGraw-Hill Book Co., Inc., New York, N. Y., 1950).

[6] G. B. Webb, private communication.

[7] D. F. Stedman, Cana. J. Res. 15B, 383 (1937); U. S. Patent 2047444 (July 14, 1936).

[8] R. B. Scott and F. G. Brickwedde, J. Research NBS 19, 237 (1937) RP1023.

Washington, July 26, 1951. 